(RESEARCH ARTICLE)

\title{
Phytochemical constituents, antibacterial screening and antioxidant activity of Albizia lebbeck (L.) Benth (Seed)
}

Yasmin Hassan Elshiekh 1, ${ }^{*}$, Reem Elsheikh Alagbash 2, Rayan Altayeb Ali 2, Fatima Omer Saad 2 and Moshera Musharaf 2

${ }^{1}$ Department of Biology and Technology, College of Applied and Industrial Sciences, University of Bahri, Bahri, Sudan.

2 Department of Pharmacognosy Faculty of Pharmacy Omdurman Islamic University, Omdurman, Sudan.

Publication history: Received on 23 June 2020; revised on 03 July 2020; accepted on 06 July 2020

Article DOI: https://doi.org/10.30574/wjarr.2020.7.1.0225

\begin{abstract}
Albizia lebbeck (L.) Benth. Traditionally plant is used as anti-asthmatic, anti-inflammatory, anti-fertility and antidiarrheal, antiseptic, anti-dysenteric, anti-tubercular, leprosy, paralysis and helminth infection. This study aimed to determine the phytochemical constituents, antioxidant and antibacterial activities. The phytochemical screening was carried out using Petroleum ether, Ethyl acetate and 70\% ethanol; preliminary phytochemical screening showed the presence of alkaloids, flavonoids, carbohydrates, tannins, coumarins and saponins in plant extracts. The seeds extract of Albizia lebbeck were tested against gram-positive and gram-negative bacteria by cup diffusion method. The Petroleum ether extract showed high activity against Escherichia coli when compared with other plant extracts. The antioxidant activity was determined by using the free radical scavenging method (DPPH). The result of antioxidant activity reflected low activity as compared with standard (Propyl gallate).
\end{abstract}

Keywords: Albizia lebbeck; Fabaceae; anti-asthmatic; anti-inflammatory; Escherichia coli

\section{Introduction}

Albizia lebbeck (L.) Benth. Are popularly known as siris is a medium to large tree [1].The genus Albizia comprises approximately 150 species; these are mostly trees and shrubs native to tropical and subtropical regions of Asia and Africa [2]. A. lebbeck belong to the family Fabaceae [1]. A. lebbeck seed are small, oblong, approximately 9 by $7 \mathrm{~mm}$ long and broad, compressed and light brown in color [3]. A. Lebbeck (L.) Benth. Of the family Fabaceae that grows up to 30 meter high. It is large erect unarmed, deciduous plant [4].In angiosperm Leguminosae is considered to be the second largest family A. lebbeck(subfamily- mimosasea) is predominantly used in the rheumatic treatment [5]. And it is nitrogen - fixing. A. lebbeck (L.) Benth. Seeds are use to cure piles, diarrhea, scrofulous swelling, aphrodisiac and tonic to the brain and it oil is applied topically inleucoderma [6]. Traditionally plant is used as anti-asthmatic, antiinflammatory, anti-fertility and anti-diarrhoeal, antiseptic, anti-dysenteric, anti-tubercular, leprosy, paralysis, helmenth infection [7], Allergic rhinitis [8]. Astringent, to treat the eye, psychoactive, flu, lung problems, pectoral problems, cough, gingivitis, abdominal tumors [9]. It is also used in the treatment of ringworms and wounds by washing the affected areas, gonorrhea, leucorrhoea and other genital diseases [10]. Plant also shows cardio protective effects [11].

\section{Materials and methods}

\subsection{Collection of Plant Materials}

Albizia lebbeck (L.)Benth. Seeds were collected from Khartoum state, Omdurman, Omdurman Islamic university and were authenticated by Dr. Yahiya Suleiman the Medicinal and Aromatic plants Research Institute.

\footnotetext{
* Corresponding author: Yasmin Hassan Elshiekh
} 


\subsection{Preparation of plant extracts}

The seeds were removed from their pods and ground to powder from using grinder-machine and the seed power to extraction by soxhlet using Petroleum ether, Ethyl acetate and 70\% ethanol.

\subsection{Phytochemical Evaluation}

The phytochemical screening of the Albizia lebbeck (Seed) was done followed the methods described by [12, 13].

\subsubsection{Continuous extraction method}

The powdered of Albizia lebbeck seed (100g) was exhaustively extracted using Soxhlet apparatus with different organic solvents in order of increasing polarity: Petroleum ether, ethyl acetate and 70 \%ethanol. Each extract was filtered and evaporated under reduced pressure using Rotary evaporator [12].The percentage of different extract yield were then calculated and tabulated. The different extracts were preserved in refrigerator till time of use.

\subsection{Biological studies}

\subsubsection{Preparation of bacterial suspensions}

One ml aliquots of a 24 hours' broth culture of the test organisms were aseptically distributed onto nutrient agar slopes and incubated at $37^{\circ} \mathrm{C}$ for 24 hours. The bacterial growth was harvested and washed off with $100 \mathrm{ml}$ sterile normal saline, to produce a suspension containing about $10^{8}-10^{9}$ C.F.U/ ml. The suspension was stored in the refrigerator at $4^{\circ}$ $\mathrm{C}$ till used. The average number of viable organisms per ml of the stock suspension was determined by means of the surface viable counting technique [14]. Serial dilutions of the stock suspension were made in sterile normal saline solution and $0.02 \mathrm{ml}$ volumes of the appropriate dilution were transferred by micro pipette onto the surface of dried nutrient agar plates. The plates were allowed to stand for two hours at room temperature for the drops to dry and then incubated at $37{ }^{\circ} \mathrm{C}$ for 24 hours. After incubation, the number of developed colonies in each drop was counted. The average number of colonies per drop $(0.02 \mathrm{ml})$ was multiplied by 50 and by the dilution factor to give the viable count of the stock suspension, expressed as the number of colony forming units per ml suspension. Each time a fresh stock suspension was prepared. All the above experimental conditions were maintained constant so that suspensions with very close viable counts would be obtained.

\subsubsection{Testing of cup diffusion method}

The cup-plate agar diffusion method of [15] was adopted with some minor modifications to assess the antibacterial activity of the prepared extracts.

One $\mathrm{ml}$ of the standardized bacterial stock suspension $10^{8}-10^{9}$ C.F.U/ ml were thoroughly mixed with $100 \mathrm{ml}$ of molten sterile nutrient agar which was maintained at $45^{\circ} \mathrm{C}$. $20 \mathrm{ml}$ aliquots of the inoculated nutrient agar were distributed into sterile Petri-dishes.

The agars were left to set and in each of these plates 4 cups (10 $\mathrm{mm}$ in diameter) were cut using a sterile cork borer (No. 4) and agar discs were removed. Alternate cups were filled with $0.1 \mathrm{ml}$ sample of each of the extracts dilutions in methanol using automatic micro-liter pipette, and allowed to diffuse at room temperature for two hours. The plates were then incubated in the upright position at $37^{\circ} \mathrm{C}$ for 18 hours. Two replicates were carried out for each extract against each of the test organisms. After incubation the diameters of the resultant growth inhibition zones were measured, averaged and the mean values were tabulated.

\subsection{Antioxidant activity}

\subsubsection{DPPH radical scavenging assay}

The DPPH radical scavenging was determined according to the method of [16].With some modification. In 96- wells plate, the test samples were allowed to react with 2.2Di (4-tert-octylphenyl) -1-Picryl-hydrazyl stable free radical (DPPH) for half an hour at $37^{\circ} \mathrm{C}$. The concentration of DPPH was kept as I $(300 \mu \mathrm{M})$. The test samples were dissolved in DMSO while DPPH was prepared in ethanol. After incubation, decrease in absorbance was measured at $517 \mathrm{~nm}$ using multi-plate reader spectrophotometer. Percentage radical scavenging activity by samples was determined in comparison with a DMSO treated control group. All tests and analysis were run in triplicate. 


\section{Results}

\subsection{Preliminary Phytochemical Screening of Albizia lebbeck seeds}

The Phytochemical Screening of Albizia lebbeck seed revealed the presence of the following metabolites as in table (1).

Table 1 The Chemical Constituents of Albizia lebbeck seed

\begin{tabular}{|c|c|c|c|}
\hline Extracts & Constituents & Test & Results \\
\hline \multirow{6}{*}{$\begin{array}{c}\text { Petroleum } \\
\text { ether }\end{array}$} & Alkaloids & Wagner's, reagents & + \\
\hline & Tannins & Braymer's test & - \\
\hline & Flavonoids & $\begin{array}{c}\text { Color in } \mathrm{NaoH} \\
\text { H2SO4 test }\end{array}$ & + \\
\hline & Carbohydrate & $\begin{array}{c}\text { Molish's } \\
\text { benedict's test }\end{array}$ & + \\
\hline & Saponins & foam test & + \\
\hline & Coumarins & - & + \\
\hline \multirow{6}{*}{$70 \%$ Ethanol } & Carbohydrate & $\begin{array}{c}\text { Molish's } \\
\text { benedict's test }\end{array}$ & + \\
\hline & Saponins & foam test & + \\
\hline & Coumarins & - & + \\
\hline & Tannins & Braymers test & + \\
\hline & Alkaloids & Wagner's, reagents & + \\
\hline & Flavonoids & $\begin{array}{c}\text { Color in } \mathrm{NaoH} \\
\mathrm{H} 2 \mathrm{SO} 4 \text { test }\end{array}$ & - \\
\hline \multirow{6}{*}{ Ethyl acetate } & Carbohydrate & $\begin{array}{c}\text { Molish's } \\
\text { benedict's test }\end{array}$ & + \\
\hline & Saponins & foam test & + \\
\hline & Coumarins & - & + \\
\hline & Tannins & Braymers test & + \\
\hline & Alkaloids & Wagner's, reagents & + \\
\hline & Flavonoids & $\begin{array}{c}\text { Color in } \mathrm{NaoH} \\
\text { H2SO4 test }\end{array}$ & - \\
\hline
\end{tabular}

Key:(+) persent ; (-)absent.

According to the results showed in table (1) the presence of alkaloids, saponins, tannins, flavonoids coumarins in Albizia lebbeck seed was agreement with $[17,18]$.

\subsection{Biological activities}

\subsubsection{Antibacterial Activity of Albizia lebbeck seeds}

The Antibacterial activity of Albizia lebbeck seeds extracts were examined against four standard bacterial strains at concentration $10 \mathrm{mg} / \mathrm{ml}$. Table (2). 
Table 2 Antibacterial Activity of Albizia lebbeck against Standard bacterial strains at concentration $10 \mathrm{mg} / \mathrm{ml}$.

\begin{tabular}{lllll}
\hline & \multicolumn{4}{c}{ Standard bacterial strains } \\
\cline { 2 - 5 } Plant extract & $\boldsymbol{E . c}$ & $\boldsymbol{P s . a}$ & $\boldsymbol{S . a}$ & $\boldsymbol{B . s}$ \\
\hline Petroleum ether & 17 & 14 & 13 & 13 \\
Ethyl acetate & 14 & 14 & 14 & 15 \\
70\% Ethanol & 15 & - & 12 & - \\
\hline
\end{tabular}

Standard bacterial strains used ;S.a =Staphylococcus aureus ,B.s = Bacillus subtilis . E.c = Escherichia coli, Ps.a = Pseudomonas aeruginosa.

The petroleum ether extract of Albizia lebbeck seeds exhibited maximum activity against Escherichia coli and minimum activity against Bacillus subtilis, Pseudomonas aeruginosa and Staphylococcus aureus. The ethyl acetate extract of the plant reflected low activity against all bacterial strains tested. While the ethanol extract of the plant showed moderate activity against Escherichia coli ,low activity against Staphylococcus aureus and no activity against Bacillus subtilis and Pseudomonas aeruginosa.

\subsubsection{Antioxidant activity of Albizia lebbeck seeds}

Table 3 Antioxidant activity of Albizia lebbeck seeds using DPPH

\begin{tabular}{lll}
\hline No & Plant extracts & \%RSA \pm SD ( DPPH ) \\
\hline 1 & Ethyl acetate & $1 \pm 0.02$ \\
2 & $70 \%$ Ethanol & $8 \pm 0.07$ \\
3 & Petroleum ether & $2 \pm 0.02$ \\
Standard & Propyl Gallate & $95 \pm 0.01$ \\
\hline
\end{tabular}

Indicated in table (3), all extracts showed low antioxidant activity as compared with standard propyl gallate.

\section{Discussion}

Medicinal plants are considered a repository of numerous types of bioactive compounds possessing varied therapeutic properties. The therapeutic potential of plants has been well explored over a very long time period. The vast array of therapeutic effects associated with medicinal plants includes anti-inflammatory, antiviral, antitumor, and analgesic. Plants are valuable source of a wide range of secondary metabolites (SMs), which are used as pharmaceuticals, agrochemicals, flavors and additives. The SMs are responsible for the medicinal value of the plants but they have very limited distribution than primary metabolites [19]. Medicinal plants are the nature gift to human brought to help them pursue a disease-free health life. Today, the whole world culture as a vast knowledge of herbal medicine, two-thirds of the new chemicals identified yearly were extracted from higher plants; moreover $75 \%$ of the world population used plants for therapy and prevention $[20,21]$. Research on plant SMs has been reported to possess various biological activities including antioxidant [22, 23], antifungal, antibacterial, antiviral [24, 25], anti-inflammatory [26] and insecticidal activities [27]. In addition, the SMs are intergrated in food preservation industries, fragrance industries, cosmetic, and agro-industrial [28]. The presence of, tannins, alkaloids, flavonoids in Albizia lebbeck was agreement with $[17,18]$. Tannin used as astringents, anti-diarrheal, asdiuretics, for stomach and duodenal tumors, and as anti-inflammatory, antiseptic, antioxidant and haemostatic pharmaceuticals. [29]. the presence of secondary metabolites especially the presence of tannins may be responsible for the various uses of this plant in traditional medicine.

\section{Conclusion}

According to the results as shown in phytochemical screening and antibacterial activity Suggest that Albizia lebbeck seed could be considered as good source for antibacterial agent in the future. Further study may be need in the field of biological activities with different solvents system and different extraction methods. 


\section{Compliance with ethical standards}

\section{Acknowledgments}

We acknowledge the Department of Pharmacognosy, Faculty of Pharmacy, Omdurman Islamic University, and the Medicinal and Aromatic plants Research Institute, for technical assistance.

\section{Disclosure of conflict of interest}

Authors have no any conflict of interest.

\section{References}

[1] Knothe G, Razon LF and Castro. (2015). "Determination of the potential of Albizia lebbeck and Albizia samanas biodiesel feed stock", DLSU Research Congress, 3, 1-8.

[2] Farag M, Gamal AE, Kalil A, Rehaily AA, Mirghany OE and Thahir KE. (2013). "Evaluation of some biological activities of Albizia lebbeck flower", Scirp, 4, 473-477.

[3] Saha M, Rahman SMM and Rahman MA. (2016). "Analysis of fatty acids of the seeds and leaf of the Albizia lebbeck fruits”, International Journal of Advances in Pharmacy, Biology and Chemistry, 5(2), 105-108.

[4] Hait M, Burgah RK and Dass C. (2009). "Chemotaxonomic study of Albizia lebbeck", Oriental Journal of Chemistry, 25(2), 455-456.

[5] Shanmugavadivu R and Subramanian MS. (2009). "Study on the phytochemical constitution of Albizzia lebbeck Benth", Asian Journal of Bioscience, 4(1), 107-109.

[6] Sharma GK and Dubey N. (2015)."Review of shirish (Albizia lebbeck) therapeutic properties”, International Journal of ayurvedic and herbal medicine, 5(1), 1683-1688.

[7] Folk Medicine at the H.E.J. (2013). "Research Institute of Chemistry International Center for Chemical and Biological Sciences".

[8] Chulet R, Jhajharia M, Pradhan P and Sharma S. (2010). "Analgesic And antipyretic Activity of Albizia Lebbeck" Pharmacology online, 3, 737-749.

[9] Sesoltani A and Paulsen SB. (2011). "Ten Medicinal Plants from Burma A literature study Thesis in pharmacognosy", 147.

[10] Hassan LJ, Umar KG andtikuIA. (2007). Nutritional Evaluation of Albizia lebbeck (L.) Pods as Source of Feeds for Livestock, American Journal of Food Technology, 2, 435-439.

[11] Sasmal S, Kumar PS and Bharathi K. (2013). "Pharmacognostical, phytochemical and pharmacological evaluation of alcoholic leaf extract of Albizia lebbeck benth International Journal of Pharmaceutical Research and life Sciences, 1(1), $94-109$.

[12] Harbone JB. (1984). Phytochemical methods.2th edition. Chapman and Hall.

[13] Sofowora. (1993). "Medicinal Plants and Traditional medicine Africa Journal of biotechnology" (11).

[14] Miles AA and Misra SS. (1938). "The estimation of the bactericidal power of the blood" Journal of the Hygiene, 38, 732 .

[15] Kavanagh F. (1972). “Analytical Microbiology”, F. Kavanagh (Ed.) vol 11. Academic Press, New York \& London, 11.

[16] Shimada, Fujikawa T and Nakamura T. (1992). "Ant oxidative properties of xanthenes on the ant oxidation of soybean oil in cyclodextrin emulsion." J Agric Food Chem, 40, 945-8.

[17] Purendra S and Teena A. (2018). "Preliminary Phytochemical and Physicochemical investigations of Albizia lebbeck (L.) Benth. Seed oils" J. IJSRMS, 4(8).

[18] Thamer MJ, Huda KA, Sara KB and Noor MN. (2019). "Isolation of flavonoids and Pharmacognostical study of Iraqi Albizia lebbeck L.”, J. Pharm. Sci. \& Res. 11(1), 239-242. 
[19] Alonso-Amelot ME.(2018). "Milk as a Natural Product: Foreign Natural and Anthropogenic Organic Compounds in It". In Stu. Nat. Prod. Chem, 56, 335-435.

[20] Shakya AK. (2016). "Medicinal plants: future source of new drugs". Int. J. Herbal. Medic, 4(4), 59-64.

[21] Zaki AA, Ross SA, El-Amier YA and Khan IA. (2018). "New flavans and stilbenes from Cyperus conglomerates". Phytochem. Let., 26, 159-163.

[22] Abd El Gawad AM, El Amier YA and Bonanomi G. (2018a). "Allelopathic activity and chemical composition of Rhynchosia minima L. D C. essential oil from Egypt”. Chem. Biodiversity, 15(1), 1700438.

[23] Elshamy AI,AbdElGawad AM, El Amier YA, El Gendy AENG and Al Rowaily SL. (2019). "Interspecific variation, antioxidant and allelopathic activity of the essential oil from three Launaea species growing naturally in heterogeneous habitats in Egypt". Flav. Frag. J., 34(4), 1-13.

[24] El-Amier YA, Abdelghany AM and Abed Zaid A. (2014). "Green synthesis and antimicrobial activity of Senecioglaucus-mediated silver nano particles”. Res. J. Pharm. Biol.Chem. Sci, 5(5), 631-642.

[25] Alghanem SM and El-Amier YA. (2017). "Phytochemical and biological evaluation of Pergularia tomentosa L. (Solanaceae) naturally growing in arid ecosystem". Int. J. Plant Sci. Eco, 3, 7-15.

[26] Tohidi B, Rahimmalek M andArzani A. (2017). "Essential oil composition, total phenolic, flavonoid contents, and antioxidant activity of Thymus species collected from different regions of Iran". Food Chem, 220, 153-161.

[27] Castillo RM, Stashenko E and Duque JE. (2017). "Insecticidal and repellent activity of several plant-derived essential oils against Aedesaegypti”. J. Am. Mosq. Cont. Assoc., 33(1), 25-36.

[28] Zuin VG and Ramin LZ. (2018). “Green and sustainable separation of natural products from agro-industrial waste: Challenges, potentialities, and perspectives on emerging approaches". In Chemistry and Chemical Technologies in Waste Valorization, 229-282.

[29] Dharmananda S. (2003). "Gall nuts and the uses of Tannins in Chinese Medicine". In: Proceedings of institute for Traditional Medicine, Portland, Oregon.

\section{How to cite this article}

Elshiekh YH, Alagbash RE, Ali RA, Saad FO and Musharaf M. (2020). Phytochemical constituents, antibacterial screening and antioxidant activity of Albizia lebbeck (L.) Benth (Seed). World Journal of Advanced Research and Reviews, 7(1), 3540. 